\title{
No topo do mundo: Everest e ações afirmativas na Pós-Graduação
}

José Antônio dos Santos* Luciana Garcia de Mello*

Resumo: Neste artigo vamos apresentar algumas iniciativas de acesso à educação e ao ensino superior proposto pelo Movimento Negro Brasileiro. Apresentamos o primeiro documento sobre políticas específicas para negros, indígenas e pessoas com deficiência do governo brasileiro e as dinâmicas nacional e internacional que levaram à entrada dessas populações nas universidades públicas. O objetivo do artigo é refletir sobre as desigualdades históricas no acesso ao ensino superior e sobre o quadro atual das políticas de ações afirmativas que se voltaram para o ingresso desses estudantes nos programas de pós-graduação no Brasil. Nesse sentido, vamos enfocar os desafios e demandas educacionais da população negra, pontuando aspectos que indicam questões dos demais grupos. Palavras-chave: Ensino Superior. Movimento Negro Brasileiro. Negros. Indígenas. Pessoas com Deficiência.

\section{Introdução}

Numa das atividades realizadas regularmente para a formação de professores e professoras da região metropolitana de Porto Alegre, fomos questionados sobre qual estágio estaria o processo de ingresso de negros e indígenas no ensino superior brasileiro. Surpreendidos pela pergunta e inspirados pelo livro que líamos, respondemos que

\footnotetext{
Doutor em História. Trabalha no Departamento de Educação e Desenvolvimento Social (DEDS/PROREXT/UFRGS). E-mail: joseants@hotmail.com " Doutora em Sociologia. É professora no Departamento de Sociologia (IFCH/ UFRGS). E-mail: lucianag.demello@gmail.com
}

Anos 90, Porto Alegre, v. 23, n. 44, p. 111-138, dez. 2016 
estávamos no início da escalada e que recém havíamos chegado ao acampamento-base do topo do mundo.

O acampamento-base do Everest, é a primeira fase da escalada pela rota da crista sudeste no lado nepalês, está localizado a 5.364 metros de altitude acima do nível do mar, é o local em que os alpinistas e aventureiros iniciam a preparação para subir as escarpas geladas do Monte. Depois de cerca de uma semana de caminhada, eles acampam nesse local e realizam vários exercícios de subidas e descidas nos primeiros níveis de escaladas, esse é o processo de aclimatação que busca as condições físicas e metereológicas ideais para o embate final até o cume. Embora possa parecer uma distância curta, os restantes 3.484 metros até o topo do Everest, localizado a 8.848 metros de altitude, constituem os maiores desafios para os melhores alpinistas do planeta (KRAKAUER, 1997).

Poucos são os privilegiados que possuem condições físicas, psicológicas e econômicas para se aventurarem na maior escalada da terra, de modo que a reserva de vagas para negros e indígenas nos programas de pós-graduações do Brasil também têm significados comparáveis à chegada ao acampamento-base do Everest. Os maiores desafios e exigências iniciam logo depois da graduação, as portas de entrada do mestrado e do doutorado têm acessos restritos e, ainda, estamos no processo inicial da criação de condições para que os aspirantes às melhores posições cheguem ao topo da carreira acadêmica. Os caminhos que levam à docência universitária são tortuosos para aqueles que terminam o ensino superior e se aventuram na pós-graduação, alguns podem obter reconhecimento intelectual e boas condições de trabalho nas maiores e melhores universidades brasileiras.

Assim como a chegada ao acampamento-base inicia a caminhada ao topo do maior pico do mundo, o acesso à pós-graduação é o início do percurso, dentre outros setores de atuação, que pode levar ao cume do mundo acadêmico. Se o trajeto é difícil e solitário, imensos são os desafios e obstáculos aos aventureiros (do conhecimento) e alpinistas (sociais), também são significativas as conquistas simbólicas e materiais para a sociedade brasileira. A reserva de vagas para negros, indígenas e pessoas com deficiência nos programas de pós-graduação de algumas universidades brasileiras, apenas deu 
início a uma nova dimensão do direito à educação superior de amplos espectros populacionais que historicamente estavam de fora do mundo acadêmico 1 .

Chegar ao pós-graduação, assim como ao acampamento-base do Monte Everest, é uma grande conquista, mas o desafio maior é ultrapassar as barreiras do Acampamento 4, que significa a finalização do doutorado e a possibilidade de ingressar profissionalmente em mercados altamente competitivos. Toda a sociedade brasileira precisa ultrapassar estereótipos, preconceitos e discriminações que restrinjam trajetórias acadêmicas e profissionais. É preciso mais do que o acesso, é necessário criar mecanismos institucionais que assegure a pluralidade epistêmica nas universidades e a desnaturalização das formas canônicas de reprodução do conhecimento, que rompam com os limites da "zona da morte" intelectual desses futuros mestres e doutores ${ }^{2}$.

Nesse artigo, iniciaremos apresentando alguns aspectos do processo de reinvindicações por escolarização e acesso ao ensino superior proposto pelo Movimento Negro Brasileiro. Em seguida, enfocaremos o primeiro documento sobre políticas específicas para negros, indígenas e pessoas com deficiência, emitido pelo Governo Federal, e as dinâmicas nacional e internacional que levaram ao ingresso dessas populações nas universidades públicas.

O objetivo do texto é refletir sobre o histórico de desigualdades no acesso ao ensino superior e sobre o quadro atual das políticas de ações afirmativas que têm se voltado para o ingresso de estudantes negros, indígenas e pessoas com deficiência nos programas de pós-graduação do Brasil. Nesse sentido, nos deteremos, principalmente, nos desafios e demandas por educação da população negra, pontuando, quando pertinente, alguns aspectos que indiquem questões relativas aos demais grupos.

\section{A luta por escolarização da população negra e a ampliação do direito à educação}

A população negra sempre creditou à educação uma importância fundamental na transformação social, revestindo-se em meio 
de integração e ascensão social permitida aos negros na sociedade brasileira. Nas iniciativas que se voltaram para a escolarização, criadas ainda no final do século XIX, a educação ou instrução era entendida como um modo dos negros serem respeitados e reconhecidos socialmente, também era meio que habilitava para a vida profissional e permitia um melhor entendimento de seus problemas que possibilitasse combater o preconceito (BARROS, 2005).

Como os demais grupos étnicos formadores da nação, principalmente imigrantes, "as pessoas de cor", desde as mais simples às principais lideranças, demonstraram estar conscientes do papel desempenhado pela educação no processo de reconhecimento das suas capacidades intelectuais. Isso está sobejamente demonstrado tanto nos estudos da imprensa negra brasileira (SANTOS, 2011), como em trabalhos clássicos sobre as relações raciais na primeira metade do século passado. Nesse sentido, Thales de Azevedo, tratando sobre a Bahia no início do século XX, ressaltava que:

\begin{abstract}
[...] as pessoas de cor, mesmo as mais humildes e escuras, fazem os maiores esforços para mandar os seus filhos à escola elementar, indo aos maiores sacrifícios para mantê-los nos cursos secundários quando já estariam em idade de ajuda-las no trabalho (AZEVEDO, 1996, p. 109).
\end{abstract}

O acesso à escolarização era entendido como um meio que poderia viabilizar a igualdade de condições nas disputas no mercado de trabalho, na ascensão social, ou, simplesmente, abrir os horizontes para o entendimento da própria realidade. Oriundos do processo de escravização a que estiveram submetidos os africanos e seus descendentes, a maioria dos negros se mantinha em condições sociais de subalternidade. $\mathrm{O}$ entendimento, não apenas das lideranças, mas também das pessoas humildes, em consonância com os desígnios da sociedade em geral, era que a escolarização os conduziria para o desenvolvimento de suas reais capacidades e abriria as portas para outros lugares de convívio com os demais brasileiros.

Em 1931, com o surgimento da Frente Negra Brasileira, primeira entidade criada por militantes negros com caráter eminentemente político, defendia-se a bandeira pela educação como algo 
necessário para superar a exclusão social e viabilizar a ascensão social da população negra. Nesse grupo, articulava-se um conceito de educação que compreendia tanto o ensino pedagógico formal quanto a formação cultural e moral do indivíduo (DOMINGUES, 2008). Desde então, o direito à educação tornou-se uma das demandas políticas fundamentais das entidades do Movimento Negro ${ }^{3}$.

O Teatro Experimental do Negro (TEN), criado em 1944, e que tinha como um de seus fundadores Abdias do Nascimento, apresentava um viés tanto cultural quanto político. A luta do grupo tinha duas dimensões principais: uma buscava o reconhecimento do valor civilizatório da herança africana e da personalidade afro-brasileira, mobilizando-se o lema da negritude; a outra tinha por objetivo elevar o status do negro na sociedade, através da abertura de oportunidades reais de ascensão econômica, política, social e cultural. No programa do TEN, publicado no seu periódico, $O$ Quilombo, já era pleiteada, dentre outras questões:

[...] a admissão subvencionada de estudantes negros nas instituições de ensino secundário e universitário, onde o negro não entrava como resultado da discriminação e da pobreza resultante da sua condição étnica; o combate ao racismo através de medidas culturais e de ensino; o esclarecimento da verdadeira imagem histórica do negro (NASCIMENTO, A.; NASCIMENTO, E., 2000, p. 210).

Demandas que foram encaminhadas para a Convenção Nacional do Negro Brasileiro, realizada em São Paulo, em 1945, e votada na assembleia final, tornando-se públicas como Manifesto à Nação Brasileira. Esse documento foi enviado a todos os partidos políticos, sendo replicada com cartas de apoio pela União Democrática Nacional (UDN), Partido Social Democrático (PSD) e Partido Comunista (PC). Contudo, a adesão nacional às ideias de democracia racial, que mantinham a ideologia da harmonia racial entre os brasileiros, e a contrariedade com as organizações que se manifestavam na defesa dos interesses da população negra, fez com que o grupo fosse acusado por alguns jornalistas de "racismo às avessas" e acabou não sendo adotada qualquer medida concreta. 
Em 1950, em comemoração ao Centenário do Final do Tráfico de Escravos, demonstrando grande apreço que eles tinham por efemérides que remetiam ao histórico de emancipação gradual da escravidão, foi realizado no Rio de Janeiro, o Primeiro Congresso do Negro Brasileiro. Organizado por intelectuais e militantes negros, em confronto aos resultados dos Congressos Afro-Brasileiros de $1934 \mathrm{e}$ 1937, foi demonstrada a insatisfação com os pesquisadores reunidos nestes congressos ${ }^{4}$. Houve manifestações contundentes contrárias àquelas representações que os tinha apenas como escravizados e objetos de laboratório dos acadêmicos. Buscavam ser reconhecidos, para além dos aspectos culturais, como construtores do país, símbolos de trabalho e organização. Reafirmavam os princípios de construção de uma "identidade negra" fundamentalmente política, voltada para lutas específicas de reconhecimento intelectual, para a resolução de problemas sociais e para a disputa da memória nacional.

Os congressistas, capitaneados por Abdias do Nascimento e Alberto Guerreiro Ramos, concluíram que a população negra fora "abandonada" pelo Estado 5 . Segundo eles, não houve por parte do governo republicano qualquer medida de integração social e econômica voltada aos negros depois da abolição formal em 1888 . Na Declaração final do Congresso, inclusive, recomendavam:

[...] o apoio oficial e público a todas as iniciativas e entidades dos brasileiros de cor, a ampliação da facilidade de instrução e de educação técnica, profissional e artística, a proteção à saúde do povo e a garantia de oportunidades iguais para todos na base da aptidão e da capacidade de cada qual (NASCIMENTO, A., 1982, p. 401).

O Congresso do Negro Brasileiro foi o primeiro evento de âmbito nacional organizado por intelectuais e militantes negros com temáticas e discussões com ênfase na resolução das principais questões da população negra. A conhecida Lei Afonso Arinos, p. ex., que incluiu o racismo entre as contravenções penais, nasceu por demanda daquele movimento contra atos de discriminação racial e de cor que eram recorrentes no país ${ }^{6}$. Também foi naquele evento que Guerreiro Ramos defendeu a tese A UNESCO e as relações 
de raça, onde propunha que o órgão internacional responsável por "promover o desenvolvimento dos processos democráticos" estudasse as "experiências sociológicas" desenvolvidas pelo Teatro Experimental do Negro para solução da "questão racial brasileira"7.

Embora tenhamos uma série de organismos que se voltaram aos interesses da população negra nos anos seguintes, esse nível de mobilização e organização nacional só foi possível a partir dos anos de 1970. Como estratégia de enfrentamento à ditadura civil-militar, jovens militantes negros começaram a se inserir nas universidades, foram criados núcleos de pesquisa e cultura que priorizavam a atuação social e comunitária, como o Grupo Cultural Palmares, fundado em Porto Alegre em 1971, e o bloco Ilê Aiyê, em Salvador, 1974. Além da atuação política mais direta no âmbito universitário, com a fundação do Centro de Estudos Afro-Asiáticos (CEAA), criado na Universidade Cândido Mendes, no Rio de Janeiro, em 1973; Grupo de Trabalho de Profissionais Liberais e Universitários Negros (GTPLUN), criado na Escola Paulista de Medicina, em 1972, e o Grupo de Trabalho André Rebouças (GTAR), na Universidade Federal Fluminense, em 1974 (RATTS, 2009).

No contexto de intensificação da luta contra o regime ditatorial e de renascimento da sociedade civil, foi fundado em 1978 o Movimento Negro Unificado Contra a Discriminação Racial, que posteriormente, adotou denominação de Movimento Negro Unificado (MNU). Diferentemente das entidades anteriores, o MNU empreendia uma luta contra a ideia de harmonia racial e, passou a combater não apenas o preconceito racial, mas a construir um ferrenho ataque à discriminação racial. A estratégia política era atuar na perspectiva estrutural, exigindo o reconhecimento do racismo e da desigualdade socioeconômica pelo Estado brasileiro.

O Programa de Ação do MNU propunha desmitificar a democracia racial brasileira; organizar politicamente a população negra transformando o Movimento Negro em organização de massa; formar alianças com sindicatos e partidos políticos para a luta contra o racismo, a exploração dos trabalhadores e para enfrentar a violência policial; introduzir nos currículos escolares a história da África e do negro no Brasil; e buscar o apoio internacional contra o racismo no país. Estratégias de atuação política que se 
No topo do mundo: Everest e ações afirmativas na Pós-Graduação

mantiveram no processo constituinte da década de 1980, e que foram fundamentais quando da promulgação da Constituição de 1988. Foi a partir da aprovação da Carta Magna que houve conquistas concretas do ponto de vista da luta antirracista, tais como: o reconhecimento da pluralidade racial brasileira; a criminalização do racismo; a criação de mecanismos jurídicos para a determinação das terras das comunidades remanescentes de quilombos, dentre outras demandas ${ }^{8}$.

Por outro lado, o ano de 1988, Centenário da Abolição, também teve importância que superava o simbólico, as entidades do Movimento Negro passaram a utilizar cada vez mais o protesto de rua para manifestar a sua insatisfação. Ocorreram em várias cidades do país as Marchas do Centenário, que afirmavam a abolição como uma conquista da população negra e exigiam maior intervenção do Estado para combater o racismo e promover a igualdade racial. Foram essas manifestações públicas de inconformidade com a realidade social em que se encontravam a maioria dos negros que abriram perspectivas para que a historiografia os representasse de outras formas, não apenas como escravizados objetos de seus senhores.

A renovação teórico-metodológica trazida pela "história vista de baixo" e o aumento dos cursos de pós-graduação deram condições para que a historiografia sobre o pós-abolição passasse a demonstrar, nas décadas seguintes, que o 13 de maio de 1888 não significou a incorporação dos "descendentes da senzala" à nação desejada. O racismo e o descaso com as condições socioeconômicas dos ex-escravizados não resolveram a "questão racial" no pós-abolição. A propalada liberdade não trouxe solução para o "problema do negro", discussão que se arrastava desde os primeiros abolicionistas, apenas jogou a culpa, pelo desajustamento social de alguns, nos próprios negros. As dificuldades de assimilação ao "mundo dos brancos", ou a ideia de que os negros foram "abandonados à própria sorte", justificadas pela incapacidade intelectual e técnica para ocupar os postos de trabalho, em função do analfabetismo e origem racial, têm sido matizadas ao trazer para o debate historiográfico outras categorias como: cidadania, racialização, racismo, mobilidade social, gerações, acesso a terra, movimentos sociais e diáspora negra em abordagens locais, transnacionais ou comparativas ${ }^{9}$. A memória 
coletiva oficial, construída sobre as datas, os heróis e os símbolos nacionais foram colocadas em discussão na esfera pública. A abolição como concessão da oligarquia nacional ou ato de bondade da princesa Isabel passou a ser questionada, do mesmo modo que a identidade nacional, construída sobre o arcabouço ideológico da mestiçagem, passou a ser fracionada pelas reivindicações de políticas específicas para a população negra.

Por outro lado, no campo da produção sociológica e demográfica sobre discriminação e desigualdades raciais, a melhoria observada nas últimas décadas, em termos de indicadores das condições de vida da população brasileira, não tem se refletido na diminuição das distâncias relativas entre brancos e negros. Conforme os trabalhos de Hasenbalg (2005), e Paixão, Rosseto e Montovanele (2010), os resultados das pesquisas demostram que pretos e pardos, segundo denominação oficial do IBGE, aqui entendidos como negros, estão expostos a desvantagens cumulativas ao longo da vida, e que essas desvantagens têm sido transmitidas para outras gerações.

Foram algumas pesquisas e documentos oficiais que instrumentalizaram as denúncias empreendidas pelo Movimento Negro nas décadas de 1970, 1980 e 1990. Também serviram para a mobilização continuada no sentido da valorização da cultura negra como eixo fundante de uma estética e identidade racial positiva, configurando dinâmicas organizativas e reivindicações que se renovaram ao longo do tempo até as políticas de ações afirmativas ${ }^{10}$.

\section{0 anos de políticas de ações afirmativas: os primeiros passos rumos ao topo}

Em 1995, com o tricentenário da morte de Zumbi dos Palmares, essas questões voltaram à discussão nacional e constituíram mote político que aglutinou o Movimento Negro entorno da Marcha Contra o Racismo, pela Cidadania e a Vida, organizada a partir de ampla mobilização com políticos e organizações sindicais, oportunidade em que foram recebidos pelo Presidente que, no mesmo dia, anunciou a criação do Grupo de Trabalho Interministerial - GTI. Pela primeira vez, rompendo com um histórico de negativas formais 
do racismo brasileiro, o Presidente da República reconhecia a existência do racismo no país e apontava para a criação de mecanismos institucionais reparatórios.

O Grupo de Trabalho Interministerial para a Valorização da População Negra foi formado por representantes de oito Ministérios, duas Secretarias do Governo e oito representantes do Movimento Negro. Dentre os 16 grupos temáticos em que esteve envolvido o GTI, nos pouco mais de dois anos de atuação, estavam questões fundamentais, como: Trabalho e Emprego; Educação; Terra (Remanescentes de Quilombo); Racismo e Violência; e Políticas de Ação Afirmativa, que passaram a inscrever a igualdade racial na agenda nacional. Esse grupo de trabalho desenvolveu uma série de ações no âmbito do governo federal e deu iniciou a uma importante reflexão sobre as políticas de ação afirmativa (BRASIL, 1998b).

$\mathrm{Na}$ abertura do Seminário Internacional Multiculturalismo e Racismo: o papel da ação afirmativa nos estados democráticos contemporâneos, realizado pelo GTI, em 2 de julho de 1996, FHC demonstrava com franqueza a sua preocupação com a continuidade das políticas que vinha propondo:

Com as reformas, já não achamos meios mais de convencer. Não conseguimos convencer o óbvio, quanto mais convencer o que não é tão óbvio, que é a necessidade de uma luta mais tenaz pela igualdade, uma luta mais tenaz contra o preconceito, contra a discriminação. Estamos pedindo à sociedade que nos ajude (CARDOSO apud BRASIL, 1998a).

O então presidente exortava a criatividade dos acadêmicos e especialistas em relações raciais presentes no Seminário, formado por brasileiros, norte-americanos e africanos, no sentido de que criassem alternativas para a implementação de ações afirmativas dirigidas aos negros que representasse a multirracialidade da nação brasileira. Mais do que isso, a sua preocupação era para que fosse criado um modelo diferente do resto do mundo, aceitável à maioria dos brasileiros e que não fugisse aos contornos da democracia racial. Era uma tarefa inglória que ele colocava sobre os ombros daqueles intelectuais, afinal, reconhecer a existência do racismo e 
das desigualdades era corriqueiro para alguns pesquisadores que há muito vinham pesquisando esses temas, difícil era definir políticas públicas específicas para grupos racialmente distintos.

Como dito acima por FHC, era difícil convencer a sociedade brasileira de que não somos uma democracia racial, quanto mais demonstrar o que não era óbvio. Havia o imperativo público da criação de mecanismos institucionais que apontassem para a recuperação de um quadro histórico de desigualdades raciais entre negros e brancos. O entendimento de boa parte da sociedade era que as políticas de ações afirmativas, ao reconhecerem os negros como população racialmente diferenciada, criariam um cisma ou fracionamento da nação. Elas fomentariam verdadeiras fronteiras raciais, tipo o modelo norte-americano, marcado pela segregação e enfrentamento racial.

O primeiro mandato do Governo de FHC (1995-1998) iniciou promissor no sentido da "valorização da população negra", possivelmente, em virtude do contexto político favorável, da pressão do Movimento Negro, e, como referido várias vezes por ele, em função da sua formação acadêmica próxima a Florestan Fernandes e Octavio Ianni, que resultou em produção intelectual no campo das relações raciais na região sul do Brasil ${ }^{11}$. No entanto, o saldo final quanto às desigualdades raciais foi de pouca realização, principalmente, porque houve resistência às políticas de ações afirmativas dentro dos principais ministérios. Soma-se a isso, a opinião pública brasileira manter certo distanciamento dessas questões naquele momento, assim como, as elites políticas e econômicas não reconhecerem iniciativas naquele sentido como estratégias que se voltavam para o desenvolvimento do país ${ }^{12}$.

Ainda que o GTI tenha apresentado resultados muito aquém do esperado, é importante destacar que havia uma proximidade entre os interesses desse grupo e o I Programa Nacional de Direitos Humanos (PNDH) instituído no dia 13 de maio de 1996. Nesse documento, o Governo Federal reconheceu a necessidade da definição de políticas públicas dirigidas para extratos populacionais específicos. Dentre os capítulos do PNDH, três são dirigidos para os seguintes grupos: "população negra", "sociedades indígenas" e "pessoas portadoras de deficiência", o que pode ser entendido como 
o início das políticas de ações afirmativas voltadas ao ensino superior no Brasil ${ }^{13}$. No primeiro caso, dentre as ações de médio prazo propostas pelo Governo Federal estavam: “[...] desenvolver ações afirmativas para o acesso dos negros aos cursos profissionalizantes, à universidade e ás áreas de tecnologia de ponta”; no longo prazo, a "[...] formulação de políticas compensatórias que promovam social e economicamente a comunidade negra” (BRASIL, 1996).

Note que o Programa foi lançado por meio do Decreto número 1.904, numa data bastante significativa para a população negra brasileira, o 13 de maio. Dentre outras demandas públicas, o documento foi resultado da já citada Marcha Zumbi dos Palmares Contra o Racismo, pela Cidadania e a Vida. O próprio Presidente da República, no prefácio do Programa Nacional de Direitos Humanos, informava: "Participei pessoalmente das comemorações relativas ao terceiro centenário da morte de Zumbi. Naquela ocasião criei um Grupo de Trabalho Interministerial para a Valorização da População Negra"14.

O PNDH apontava para a necessidade de "[...] assegurar às sociedades indígenas uma educação escolar diferenciada, respeitando o seu universo sociocultural", para as pessoas portadoras de deficiência era definida a "[...] criação de normas relativas ao acesso do portador de deficiência ao mercado de trabalho e no serviço público, nos termos do art. 37, VIII da Constituição Federal”. Ou seja, existia na Constituição de 1988 a prerrogativa da reserva percentual de cargos e empregos para pessoas portadoras de deficiência, o que veio a ser assegurado pela Lei 8.112/90, art. 5ํㅗ $\S 2^{\circ}$, que dispôs sobre o Regime Jurídico dos Servidores Públicos da União, e estabeleceu a reserva de até $20 \%$ das vagas disponíveis nos concursos públicos.

Também a Lei 8.213/91, conhecida como Lei de Cotas, definiu aspectos legais sobre os Planos de Benefícios da Previdência Social e deu outras providências, criando um percentual de $2 \%$ na contratação de pessoas com deficiências nas empresas com cem ou mais funcionários, com limitação de até $5 \%$ para as que têm acima de mil empregados. Soma-se a isso, a Lei no 8.666/93, no art. 24, inciso XX (Lei das Licitações), que tornou dispensável a licitação para a contratação de entidades representativas dos portadores de 
deficiências físicas para a prestação de serviços ou fornecimento de mão-de-obra junto a entidades da Administração Pública.

Conforme acima, já existia legislação específica que garantia vagas para pessoas com deficiência no mercado de trabalho, o que não era assegurado a negros e indígenas nesse segmento. $\mathrm{O}$ PNDH foi o primeiro documento do Governo Federal que abriu perspectivas diferenciadas aos negros no acesso aos cursos profissionalizantes e universidades, assim como se preocupou com a educação escolar indígena. Mais do que definir políticas públicas diferenciadas a essas populações, desde então, o Estado passou a desempenhar papel importante na organização e no encaminhamento de discussões relativas à questão racial brasileira.

A reserva de vagas no ensino superior tornou-se realidade somente nos anos 2000, após a III Conferência Mundial da Organização das Nações Unidas - ONU - contra o racismo, a discriminação racial, a xenofobia e as formas conexas de intolerância, realizada em 2001 na cidade de Durban na África do Sul. Em 08 de setembro de 2000, em atendimento à Comissão de Direitos Humanos das Nações Unidas, o Governo FHC criou o Comitê Nacional para a Preparação da Participação Brasileira nessa conferência. Foi nesse contexto, permeado por uma série de Pré-Conferências Temáticas Regionais, organizadas pelo Comitê em vários estados, que se estruturou a Conferência Nacional Contra o Racismo e a Intolerância. Esta mobilização teve como resultado o documento que pautou a participação brasileira na Conferência Mundial Contra o Racismo, momento em que as políticas de ações afirmativas entraram de vez na agenda política nacional.

A implementação das políticas de ações afirmativas no ensino superior brasileiro iniciou de forma descentralizada e sem qualquer articulação do Governo Federal. A primeira iniciativa foi, em 2001, na Universidade Estadual do Rio de Janeiro, a partir de demandas e interesses estaduais. A seguir, as reservas se estenderam para as demais universidades do Estado, como a Universidade Estadual do Norte Fluminense (UENF), e, em 2004, por necessidades e iniciativas próprias, para a Universidade de Brasília. Foi a partir de então, que as universidades federais passaram a inserir a reserva de vagas 
No topo do mundo: Everest e ações afirmativas na Pós-Graduação

para negros, indígenas e estudantes oriundos de escolas públicas nos seus regimentos, principalmente, por pressões do Movimento Negro que foram encampadas pelos Governos de Luiz Inácio Lula da Silva $(2003-2010)^{15}$.

Nesse período, tivemos a oportunidade de entender algumas das justificativas contrárias a reserva de vagas para negros na Universidade Federal do Rio Grande do Sul - UFRGS. Naquela oportunidade, fazíamos parte da Comissão criada pelo Conselho Universitário para elaborar o documento que balizaria o ingresso de negros e indígenas na UFRGS e fomos surpreendidos, por um lado, com o desconhecimento da maioria da Comissão sobre o histórico das desigualdades raciais no país, por outro, com o discurso de que a reserva de vagas iria ferir o princípio do mérito daqueles que estavam preparados para passar no vestibular. A obrigatoriedade de que a reserva de vagas fosse destinada apenas a negros e indígenas, como inicialmente sugerido, tomou corpo e passou a abarcar também os estudantes oriundos da escola pública. Embora sendo indicados por seus pares para elaborar o documento inclusivo, havia manifesta contrariedade de alguns professores, para o ingresso diferenciado de negros na Universidade, contrariedade que era muito maior do que em relação aos indígenas, p. ex. A estratégia que permitiu a aprovação do documento foi a definição de $30 \%$ das vagas para estudantes oriundos da escola pública, percentual que destinaria $15 \%$ para estudantes autodeclarados negros advindos desse meio ${ }^{16}$.

Naquela oportunidade, não tivemos dúvidas sobre os interesses que estavam presentes na Comissão no sentido de arrefecer conquistas que eram inevitáveis naquele contexto social, político e econômico, afinal, o Governo Federal havia condicionado a liberação de recursos via Ministério da Educação apenas às universidades federais que implementassem a reserva de vagas para negros e indígenas. Portanto, era obrigatório assegurar um percentual de vagas de ingresso ao ensino público federal, mas definir essa política apenas por meio do ensino público era dificultar o ingresso daqueles postulantes negros que estavam mais bem preparados. Tínhamos uma classe média negra que era consumidora de bens e produtos e tinha acesso a escolas privadas, ou seja, ocuparia com mais facilidade as vagas disponíveis. Posteriormente, a não 
ocupação integral das vagas destinadas aos negros foi motivo para justificativas que pregavam o fim das cotas, ao mesmo tempo em que colaborava para que a questão racial desaparecesse por meio de discussões sociais ou classistas.

A definição identitária da população afro-brasileira ou afrodescendente como negra foi uma conquista do Movimento Negro que se deu, principalmente, no processo de reconstituição democrática do país iniciado nos anos de 1970. O termo negro passou a ser dotado de nova significação não mais restrita aos escravizados, mas que se propunha a recuperar a dignidade e a autoestima daqueles que se identificavam como originários do processo de escravização africana. Negro passou a ser a palavra de ordem que aglutinou todos aqueles (as) que se autoidentificavam a partir da cultura, da religiosidade e de aspectos fenotípicos afro-brasileiros, o que passou a definir contornos fundamentais na definição de estratégias políticas na garantia de direitos.

Anteriormente, a população afro-brasileira ou afrodescendente perdia-se numa plêiade de autoidentificações que remetia a uma palheta cromática e suposta origem comum, nesse processo, os autodeclarados negros passaram a constituir mais da metade da população brasileira. Esse é um aspecto fundamental para que políticos e funcionários responsáveis por políticas públicas sejam convencidos da importância de ações e legislação dirigidas a esse extrato populacional. Além de uma propalada herança cultural africana que subsumiu na nacionalidade, temos um expressivo agente populacional que elege governantes e reivindica direitos, também trabalha e produz em seguimentos fundamentais da economia brasileira, atuando não apenas como produtores mas também como consumidores de bens e produtos.

Conforme demonstramos rapidamente, mesmo que já existisse a garantia constitucional para as ações afirmativas no Brasil, assim como a indicação de reserva de vagas para determinados segmentos - pessoas com deficiência e mulheres -, o sistema jurídico contrário a esse processo só foi acionado quando da introdução do sistema de cotas para estudantes negros e egressos das escolas públicas nas universidades públicas estaduais e federais. Interessante perceber que, segundo dados do PNAD/IBGE 2012, a "população 
economicamente ativa" é distribuída em 52,2\% para negros e 47\% para brancos; entre aqueles que fazem parte da "população ocupada" $51,7 \%$ são negros, enquanto $47,5 \%$ se identificam como brancos. Ou seja, aqueles que são a maioria da população e constituem o maior número em atividade econômica, portanto, são os principais responsáveis por manter as instituições públicas de ensino com o pagamento de impostos, são eles que estão fora das universidades.

A inserção dessas populações no ensino superior é acima de tudo uma demanda por justiça social. As disputas em torno dessa política revelam que a complexidade dessa contestação encontra forte ressonância na ordem social estabelecida e nos valores há tempos internalizados. Segundo a concepção de Honneth (2014), na sociedade moderna, a ideia de justiça está relacionada ao valor ético da liberdade. Essa, por sua vez, pode ser compreendida como sinônimo de autonomia, que diz respeito ao contexto das relações sociais que a asseguram e em conjunção com o que significa ser autônomo. As condições para autonomia pessoal só podem ser encontradas nos próprios sujeitos e nas relações sociais de reconhecimento recíproco, portanto, a autonomia é alcançada por vias intersubjetivas. Em consequência, nessa perspectiva teórica, o principio de autonomia não pode ser separado da ideia de justiça social, isto é, das reflexões sobre como instituir uma sociedade capaz de abrigar os interesses e necessidades de seus membros.

$\mathrm{Na}$ teoria honnethiana é justamente a liberdade do indivíduo que se torna algo com um significado superior na ordem social, sendo que a partir da compreensão do que é a liberdade para cada um é possível chegar ao estabelecimento de uma ordem social legítima. Todavia, há uma multiplicidade de concepções de liberdade, levando a um questionamento permanente sobre qual o conteúdo do princípio de autodeterminação; ou ainda, quais são as condições necessárias para realmente possibilitar a autonomia do indivíduo. Ele argumenta que há três modelos distintos de liberdade: a jurídica, a moral e a social. A primeira concede ao indivíduo a oportunidade, controlada pelo Estado de direito, de protelar as decisões éticas por um determinado tempo, de modo a poder ponderar a sua própria vontade; já a liberdade moral, outorga ao indivíduo a possibilidade 
de recusar determinadas imposições de ação, alegando razões justificáveis (HONNETH, 2014, p. 165-166). Essas duas formas de liberdade possuem um caráter parasitário em relação às práticas sociais, que não somente as precedem, mas também a elas devem o seu verdadeiro direito de existir.

De modo diferente, a liberdade social apresenta contextos substancias de ação, que contém objetivos com reconhecido valor e laços vinculantes. Se a liberdade jurídica e a liberdade moral apresentam possibilidades de liberdade, é no social que se apresenta a realidade da liberdade. Assim, a liberdade social permite orientar a nossa concepção de justiça, pois lança luz sobre as possibilidades de realização social. Honneth retoma o conceito de eticidade de Hegel para mostrar que há no social uma rede de rotinas e obrigações, que se relacionam com certas atitudes morais, enquanto práticas sociais e/ou enquanto valores institucionalizados socialmente. Desse modo, o justo deve ser pensado em relação a esses valores gerais racionais compartilhados em uma sociedade. Daí decorre o entendimento de que é no social que se encontram os meios e as condições para execução da liberdade. Os indivíduos criam expectativas morais de que seus papeis sejam reconhecidos, possibilitando assim a realização da liberdade social; quando isso não ocorre, percebe-se um desajuste entre as demandas de justiça e o que já se encontra institucionalizado. Isso nos leva a argumentar que, na sociedade brasileira, as bases sociais e morais para a realização do reconhecimento da questão racial - essa entendida como demanda por justiça social - não estão dadas.

As disputas em torno das ações afirmativas revelam, em parte, a ausência de um acordo intersubjetivo partilhado entre os brasileiros no que se refere ao enfrentamento do racismo e às desigualdades socioeconômicas. Ao encaminhar a proposta de ações afirmativas para a população negra o governo brasileiro rompia com a tradição formal republicana que teimava em não reconhecer o racismo, e questionava a ideologia que definiu historicamente o Brasil como país de misturas e hibridismos raciais e culturais. Nisso, vem colaborando para que a sociedade compreenda melhor sua própria história de construção das diferenças ${ }^{17}$. A reserva de vagas nos 
No topo do mundo: Everest e ações afirmativas na Pós-Graduação

cursos de pós-graduação é apenas mais uma etapa nesse processo de reconhecimento nacional, justiça social e reconhecimento de demandas por igualdade de oportunidades.

\section{@ Cotas na Pós-Graduação: chegaremos ao Acampamento 4?}

No dia 12 de maio de 2016, em um dos últimos atos como Presidenta do Brasil, Dilma Rousseff divulgou portaria normativa que estipulou prazo para que as instituições federais apresentassem propostas de políticas afirmativas para negros, indígenas e pessoas com deficiências nos programas de pós-graduação. As universidades e os institutos federais de educação tinham o prazo de 90 dias para apresentar propostas de ingresso nos mestrados, mestrados profissionais e doutorados. Com a entrada do atual presidente, essa determinação está pendente.

Nessa última parte do artigo, vamos demonstrar alguns dados e procurar responder qual a razão de se reservar cotas no sistema de pós-graduação. Evidentemente, que não se pode postular motivos que sejam discrepantes em relação àqueles mobilizados para sustentar tal política no nível de ensino imediatamente anterior, qual seja a graduação. No entanto, como demonstrado anteriormente, a adoção de política de cotas foi possível em razão de uma negociação nacional que resultou em um sistema que combina critérios socioeconômicos com critérios raciais. Houve certo consenso para a adoção de cotas no ensino superior que levou em conta principalmente a defesa da valorização do ensino público. Ocorre que o público alvo principal de tal política são exatamente os alunos que ingressaram no sistema universitário no período recente e, em larga medida, passaram por uma formação semelhante. Nesse sentido, argumenta-se que tal reserva relaciona-se a possibilidade de participação paritária, tal como compreendida por Nancy Fraser.

Fraser (2013) adota um conceito multidimensional de justiça que possui três dimensões: redistribuição, reconhecimento e representação. O princípio normativo válido para avaliar reivindicações com implicações multidimensionais é o da paridade participativa 
que refere-se a necessidade de estruturas que permitam a todos os indivíduos participar como iguais na vida social. A viabilização desse modo de participação seria dada pela remoção de obstáculos institucionalizados, que podem se apresentar de três formas distintas: a) nas estruturas econômicas, restringido os meio necessários para que as pessoas possam interagir umas com as outras como iguais, provocando injustiça distributiva ou má-distribuição; b) nas hierarquias institucionalizadas de valor cultural, que negam as pessoas a posição necessária para participar das interações de modo igualitário, causando desigualdades em termos de status ou mal reconhecimento; c) nas regras estabelecidas, que negam a igualdade em deliberações públicas e na tomada de decisões democráticas, provocando injustiça política ou má-representação (FRASER, 2013, p. 752).

Ainda que tenham ocorrido importantes modificações na remoção de alguns obstáculos institucionalizados no acesso à educação superior, ainda vivenciamos uma situação de confinamento racial no universo acadêmico brasileiro muito próxima daquela realidade apontada por Carvalho (2005-2006). Considerando algumas das principais universidades de pesquisa do país (UFRGS, UnB, UFSCAR, USP, UFRJ, Unicamp, UFMG), na época, tinha-se um contingente de aproximadamente 18.400 professores universitários, a maioria com título de doutor. Nesse universo, 99,6\% eram brancos e apenas $0,4 \%$ negros - não havia um único indígena.

Conforme o mesmo autor

Se escolhermos aleatoriamente um professor desse grupo, o perfil básico que encontraremos será o seguinte: esse professor (ou professora) foi um(a) estudante branco (a) que teve poucos colegas negros no secundário, pouquíssimos na graduação e praticamente nenhum no mestrado e no doutorado; como aluno (a) sempre estudou com professores brancos. Desde que ingressou na carreira docente faz parte de um colegiado inteiramente branco, dá aulas para uma maioria esmagadora de estudantes brancos na graduação e de 100\% de pós-graduandos brancos. Além disso, os assistentes e colegas do seu grupo de pesquisa são todos brancos (CARVALHO, 2005-2006, p. 92). 
O autor postulava a possibilidade de que, nas faculdades mais fechadas e elitizadas, um docente-pesquisador desenvolvesse por décadas o seu trabalho acadêmico sem nunca conviver com um estudante ou docente negro. $\mathrm{O}$ resultado desse confinamento acadêmico, além da ausência de contato interracial em condições de igualdade, seria o empobrecimento epistêmico causado pela ausência de saberes e conhecimentos negros e indígenas.

Embora a população que se identifica como negra, que é a soma de pretos e pardos, represente a maior parte da população brasileira (52,9\%), entre os estudantes de pós-graduação, eles são apenas 28,9\% do total. Segundo dados da Pesquisa Nacional por Amostra de Domicílios (PNAD), o número de estudantes negros, no mestrado e no doutorado mais do que duplicou de 2001 a 2013, passando de 48,5 mil para $112 \mathrm{mil}$. Se considerarmos apenas os estudantes autodeclarados pretos, o número passou de 6 para 18,8 mil, um aumento significativo de mais de três vezes. ${ }^{18}$

São números significativos que demonstram o crescimento da inserção dos negros nos programas de pós-graduação, mas também o expressivo número de estudantes que se declaram brancos, de 218,8, para 270,6 mil, o que deve ser o resultado, ainda, do aumento dos programas de pós-graduações de uma forma genérica. Esse crescimento não significa que todos os ingressantes chegaram ao final dos cursos, muito menos que esses mestres e doutores entraram nas universidades como professores, nem direcionaram suas pesquisas para temáticas vinculadas às questões da população negra. E corrente a ideia do eurocentrismo que permeia boa parte dos cursos de mestrado e doutorado, bem como o epistemicídio que não reconhece das contribuições indígenas, africanas e asiáticas para a construção dos conhecimentos científicos. Ainda é pequeno o número de linhas de pesquisa e de professores orientadores nas pós-graduações brasileiras que tenham proximidade e pertinência intelectual para trabalhar com questões e temáticas relativas a essas populações.

Por outro lado, segundo levantamento divulgado pelo Conselho Nacional de Desenvolvimento Científico e Tecnológico (CNPq), das 91.103 bolsas de formação e pesquisa, em janeiro de 2015, 26\% foram destinadas a estudantes negros e $58 \%$ para brancos. O percentual de bolsas destinadas aos indígenas não atingia 1\% daquele 
total de estudantes de pós-graduação, enquanto cerca de 11\% dos estudantes não declararam o seu pertencimento étnico-racial. $\mathrm{O}$ que nos dá uma ideia das desigualdades de negros e indígenas em relação aos estudantes brancos, o acesso a recursos mínimos, como as bolsas de estudo, para a finalização de cursos de pós-graduação é o dobro desse último grupo em relação aos demais. Embora, tenhamos informações, de acordo com o Censo da Educação Superior de 2013 (MEC/INEP), que o número de estudantes indígenas frequentando a educação superior naquele ano era de 13.687 , o que representava contingente bastante inferior aos demais há nítidas diferenças no acesso a bolsas. Como se visualiza nas séries históricas ate 2014, divulgadas na página do CNPq, há muita desigualdade na distribuição dos recursos. As mulheres, descritas de uma forma genérica (feminino), pois não há distinção entre negras e brancas, constituem a menor parcela dos estudantes que recebem bolsas; assim como, as regiões sudeste e sul, respectivamente, são as que recebem o maior número de bolsas.

Diante do que vimos tratando até aqui, estas últimas páginas não poderiam ser usadas senão para apontar a necessidade da articulação de diferentes ações públicas para a superação das desigualdades raciais na educação como um todo, sendo o acesso à pós-graduação um dos aspectos a serem tratados nesse processo. A melhoria das escolas, principalmente as públicas, pois é nelas que está a grande maioria dos jovens negros é uma questão emergencial. Artes (2015), p. ex., relata que de cada 100 estudantes brancos que finalizaram o ensino médio, 49 ingressaram em cursos de graduação, índice que chega a 28 para os negros. Dados que indicam desigualdades no acesso ao ensino superior iniciadas na etapa final da educação básica. É também no ensino médio que as escolhas profissionais são definidas, a separação dos grupos étnicos e de gênero por áreas de conhecimento, estando as mulheres mais concentradas nos cursos de saúde e educação e os homens nas ciências exatas e da natureza. Um passo importante na superação das desigualdades por sexo, raça e outras diferenças, no acesso a cursos de maior ou menor prestígio, que vão ter reflexos nas escolhas da pós-graduação, é entender os limites e motivações dessas escolhas anteriores. A reserva de vagas no ensino superior, assim como a perspectiva de ingresso diferenciado 
na pós-graduação, é uma estratégica fundamental para assegurar o acesso de negros, indígenas, pessoa com deficiência e demais interessados, a espaços de reprodução de poder.

Nesse sentido, a pós-graduação é a etapa mais valorizada da educação, uma vez que a partir dela podemos construir epistemes relacionais que contemplem a multiplicade de saberes que comungam a nossa nacionalidade; mobilizar consciências e práticas com sentidos críticos transformadores em substituição a conhecimentos canônicos que se locupletam no interior das universidades; redefinir o papel social dos professores-pesquisadores para o reconhecimento dos outros como formadores de si mesmos; reconhecer o caráter histórico, inacabado e relativo do conhecimento a partir da multiplicidade de atores e vozes que deixaram registros e permeiam a realidade; rever conceitos, métodos e contribuições que contemplem saberes os mais diversos; finalmente, introduzir nesses espaços atores sociais comprometidos com a definição de novos referenciais para a resolução dos problemas e desafios do país.

Sem dúvida isto constitui um programa de uma nova universidade. Pode ser uma utopia, desde que seja entendida como um projeto coletivo que contemple questões e desejos de todos e de todas que acreditam num futuro melhor. Como o desafio de chegar ao topo do Monte Everest, que possui quatro acampamentos de aclimatação e um grupo privilegiado de alpinistas, esse programa inclusivo de uma nova universidade se mostra distante, mas assim como a subida que leva ao cume mais alto da terra, vamos galgando passo a passo, um depois do outro, todos os obstáculos ${ }^{19}$.

\section{ON TOP OF THE WORLD: THE EVEREST AND AFFIRMATIVE ACTION IN POSTGRADUATE COURSES}

Abstract: In this article we will start presenting some aspects of process for enrollment and access to higher education proposed by the Brazilian Black Movement. Then we focus on the first document on specific policies for blacks, indians and persons with disabilities, issued by the Federal Government, and the national and international dynamics that led to the entry of these populations in public universities. The purpose of the paper is to reflect on the historical inequalities in access to higher education and about the current framework of 
affirmative action policies that have turned to the entrance of black students, indigenous people and people with disabilities in postgraduate programs in Brazil. In this sense, we will hold in mainly the challenges and demands for education of the black population, punctuating, where relevant, some aspects that indicate issues with the other groups.

Keywords: Higher Education. Brazilian Black Movement. Blacks. Indigenous people. Disabled people.

\section{Notas}

${ }^{1}$ Primeira universidade federal a adotar a reserva de vagas na graduação, a Universidade de Brasília também foi a primeira a adotar cotas na pós-graduação. Desde 2014, os Programas de Pós-Graduação em Antropologia e Sociologia criaram regras para esse fim. Recentemente, as Pós-Graduações em História da Universidade Federal Fluminense e Universidade Federal do Rio Grande do Sul - UFRGS, assim como a Pós-Graduação em Antropologia da UFRGS, também criaram políticas de acesso diferenciado para estudantes autodeclarados negros, indígenas e pessoas com deficiência. No caso da História da UFRGS, o ingresso também foi franqueado a pessoas identificadas como trans.

${ }^{2}$ Do acampamento-base do Everest até o seu topo existem quatro acampamentos que são usados para o descanso e a aclimatação necessários para a subida final ao cume. O Acampamento 4 é o último, foi montado próximo dos $8 \mathrm{mil}$ metros de altitude, na chamada "zona da morte", onde a altitude e o frio são implacáveis com os alpinistas.

${ }^{3}$ A definição de Movimento Negro, em letras maiúsculas e no singular, é tida por boa parte dos intelectuais e militantes como um "essencialismo estratégico". Embora considerem a diversidade das organizações negras, desde a Frente Negra Brasileira até os grupos atuais, compostos por diferentes atores políticos e estratégias de atuação, são reconhecidas como dirigidas aos mesmos objetivos - contra o racismo e a favor de melhores condições de vida para a população negra brasileira. Cf. Pereira (2010).

${ }^{4}$ Para maiores informações sobre os Congressos Afro-Brasileiros realizados em Recife, 1934, e Salvador, 1937, ver Siqueira (2005).

${ }^{5}$ Além dos citados acima, fizeram parte do Congresso: Aguinaldo Camargo, Geraldo Campos de Oliveira, José Pompílio da Hora, Ruth de Souza, Ironides Rodrigues, Sebastião Rodrigues Alves, Maria de Lourdes Vale Nascimento, o senador Hamilton Nogueira, Claudino José da Silva (deputado federal do Partido Comunista), dentre outros. O Congresso teve representações políticas

Anos 90, Porto Alegre, v. 23, n. 44, p. 111-138, dez. 2016 
de São Paulo, Bahia, Minas Gerais, Rio de Janeiro e Rio Grande do Sul com a Sociedade Floresta Aurora.

${ }^{6}$ A Lei no 1.390, de 3 de julho de 1951, de autoria do deputado federal Afonso Arinos de Melo Franco, diferencia-se da legislação atual, na medida em que o racismo deixou de ser apenas contravenção penal e passou a ser considerado crime inafiançável. Cf. Artigo 5o da Constituição Federal, regulamentado pela Lei Federal no 7.716, sancionada em 5 de janeiro de 1989.

${ }^{7} \mathrm{O}$ livro $O$ negro revoltado, de Abdias do Nascimento, foi originalmente publicado em 1968. A publicação têm boa parte dos pareceres e teses aprovadas no I Congresso do Negro Brasileiro, além das principais resoluções de alguns dos eventos citados anteriormente.

${ }^{8}$ No processo constituinte, desde 1985, o Movimento Negro se mobilizou com uma série de eventos realizados por todo o país. Também participou da Subcomissão de Negros, Populações Indígenas, Pessoas Deficientes e Minorias que subsidiou os constituintes com questões de seu interesse.

${ }^{9}$ Nesse sentido, ver a Revista Brasileira de História, v. 35, n. 69 de 2015, que traz o dossiê intitulado, O pós-abolição no mundo atlântico, que elencou uma série de artigos que tratam de temáticas relativas ao período sobre diversos aspectos, personagens e cronologias.

${ }^{10}$ As ações afirmativas são políticas públicas que se destinam para pessoas pertencentes a grupos historicamente discriminados e vitimados pela exclusão socioeconômica. No caso da educação, as medidas podem ser implementadas por meio de bolsas de estudo, reserva de vagas ou bônus que são somados ao resultado de provas. Elas podem ser entendidas como prevenção a discriminações ou reparação a danos sofridos, o objetivo é assegurar o acesso a posições sociais importantes a membros de grupos que representem a diversidade demográfica da sociedade.

${ }^{11}$ Foi no Governo FHC, p. ex., em 20 de novembro de 1996, que foi criada a Lei 9.315 que inscreveu o nome de Zumbi dos Palmares no Livro dos Heróis da Pátria, que se encontra no Panteão da Liberdade e da Democracia, em Brasília. ${ }^{12}$ Embora a relação entre educação e desenvolvimento econômico no capitalismo seja uma questão controversa, existem estudos que demonstram o aumento da capacidade produtiva dos países com níveis de escolaridade mais alta. Cf. Valverde; Stocco, 2009.

${ }^{13}$ Abdias do Nascimento, no projeto de Lei n⿳o 1.332, de 1983, propôs "ação compensatória" que previa a reserva de $40 \%$ das vagas para homens e mulheres negras na seleção de candidatos ao serviço público; bolsas de estudos; incentivos às empresas privadas para a eliminação da prática da discriminação 
racial; incorporação da imagem positiva da família negra no sistema de ensino e introdução da história das civilizações africanas e do africano no Brasil. O projeto não foi aprovado no Congresso Nacional, mas as reivindicações do Movimento Negro continuaram.

${ }^{14}$ Cf. Brasil (1998a).

${ }^{15}$ Em 14 de janeiro de 2001, o jornal Folha de São Paulo publicou, no caderno Cotidiano, extensa matéria enfocando o Exame Nacional de Cursos, popularmente conhecido como "provão". Estratificada por cor ou raça, classificação que os estudantes se autoatribuíam, o jornal traçou o perfil dos 197 mil alunos formandos nos diversos cursos submetidos ao exame. Segundo a Folha, nos 18 cursos superiores analisados pelo MEC, no exame de 2000, os negros eram apenas $15 \%$ dos formandos, muito embora eles constituíssem $45,2 \%$ da população nacional na época. Os índices de desigualdade racial no interior de cada curso eram bastante elevados, o que serviu como denúncia pública sobre o enorme quadro de desigualdades entre negros e brancos existentes no acesso e na diplomação do ensino superior brasileiro.

${ }^{16}$ O Programa de Ações Afirmativas foi aprovado pelo Conselho Universitário da UFRGS no dia 29 de junho de 2007. A Decisão n⿳o 134/2007 definiu, além dos $30 \%$ para egressos de escola pública, 10 vagas para o ingresso especial de indígenas, mediante a escolha de cursos de interesse de suas comunidades. $\mathrm{O}$ Programa foi avaliado em 2012, tendo sido aprovado seus resultados e a sua continuidade por mais 10 anos, conforme a Decisão no 268/2012.

${ }^{17}$ Queiroz e Santos (2006) realizaram um estudo comparativo com a pesquisa Racismo Cordial realizada pelo Datafolha, em 1995. Nesse ano, 48\% dos entrevistados concordavam com a reserva de vagas para negros na educação e no mercado de trabalho; em 2006, o percentual de aprovação alcançou 65\%. Em todos os segmentos raciais, níveis de renda e escolaridade mais elevados a maior parte dos entrevistados mostrava-se favorável às cotas. Também foi constatado que a maior rejeição às cotas, nas duas pesquisas, eram nos grupos com escolaridade e renda mais altos.

${ }_{18}^{18}$ Tokarnia (2015).

${ }^{19}$ Desde as primeiras expedições da década de 1920; a chegada ao cume em 1953; ao trágico evento de 1996, quando oito alpinistas morreram próximo ao cume, o Everest tem sido utilizado como símbolo de desafio, conquista, heroísmo e aventura que se mantém em todo o mundo. Por outro lado, conforme demonstrado por Birrel (2011), a história do Monte Everest é marcada por privilégios de homens europeus de classes privilegiadas que fizeram da chegada ao cume a sede de um dos mais privilegiados clubes do mundo. 
No topo do mundo: Everest e ações afirmativas na Pós-Graduação

\section{Referências}

ARTES, Amélia C. A.; CARVALHO, Marília P. de. O trabalho como fator determinante da defasagem escolar dos meninos no Brasil: mito ou verdade? Cadernos Pagu, Campinas, n. 34, p. 41-74, jan./jun. 2010.

AZEVEDO, Thales de. As elites de cor numa cidade brasileira: um estudo de ascensão social \& classes sociais e grupos de prestígio. Salvador: EDUFBA; EGBA, 1996.

BARROS, Surya Aaronovich Pombo de. Negrinhos que por ahi andão: a escolarização da população negra em São Paulo (1870-1920). 2005. Tese (Mestrado em Educação)-Faculdade de Educação, Universidade de São Paulo, São Paulo, 2005.

BIRREL, Susan. Abordando o Monte Everest: da intertextualidade e do passado como narrativa. Recorde: Revista de História do Esporte, Rio de Janeiro, v. 4, n. 2, dez. 2011.

BRASIL. Atos e palavras do Presidente Fernando Henrique Cardoso, 1995 a 1998. In: _ Construindo a democracia racial. Brasília, DF: Presidência da República; Secretaria de Comunicação Social, 1998a. Documento sem paginação. Disponível em: <http://www.biblioteca.presidencia.gov.br/presidencia/ ex-presidentes/fernando-henrique-cardoso/publicacoes/construindo-a-democracia-racial>. Acesso em: 20 jul. 2016.

. Grupo de Trabalho Interministerial Para Valorização da População

Negra. In: . Construindo a democracia racial. Brasília, DF: Presidência da República; Secretaria de Comunicação Social, 1998b. Documento sem paginação. Disponível em: <http://www.biblioteca.presidencia.gov.br/presidencia/ ex-presidentes/fernando-henrique-cardoso/publicacoes/construindo-a-democracia-racial>. Acesso em: 20 jul. 2016.

. I Programa Nacional de Direitos Humanos. Brasília, DF: Ministério da Justiça, 1996. Disponível em: <http://www.direitoshumanos.usp.br/index. $\mathrm{php} /$ Direitos-Humanos-no-Brasil/i-programa-nacional-de-direitos-humanos-pndh-1996.html>. Acesso em: 20 jul. 2016.

CARVALHO, José Jorge. O confinamento racial do mundo acadêmico brasileiro. REVISTA USP, São Paulo, n. 68, p. 88-103, dez./fev. 2005-2006.

DOMINGUES, Petrônio. A nova abolição. São Paulo: Selo Negro, 2008.

FONSECA, Marcus V. Apontamentos em relação às formas de tratamento dos negros pela história da educação. História da Educação, Pelotas, v. 13, n. 28, p. 29-59, maio/ago. 2009.

Anos 90, Porto Alegre, v. 23, n. 44, p. 111-138, dez. 2016 
FRASER, Nancy. Justiça anormal. Revista da Faculdade de Direito, São Paulo, v. 108, p. 739-768, jan./dez. 2013.

HASENBALG, Carlos. Discriminação e desigualdades raciais no Brasil. 2. ed. Belo Horizonte: Ed. UFMG, 2005.

HONNETH, Axel. El derecho de la libertad: esbozo de uma eticidad democrática. Madrid: Katz, 2014.

JACCOUD, Luciana. A construção de uma política de promoção da igualdade racial: uma análise dos últimos 20 anos. Brasília, DF: IPEA, 2009.

KRAKAUER, Jon. No ar rarefeito: um relato da tragédia no Everest em 1996. São Paulo: Cia. das Letras, 1997.

LIMA, Marcos Eugenio O.; COSTA NEVES, Paulo S.; BACELLAR E SILVA, Paula. A implantação de cotas na universidade: paternalismo e ameaça à posição dos grupos dominantes. Revista Brasileira de Educação, v. 19, n. 56. p. 141-163, jan./mar. 2014.

MOEHLECKE, Sabrina. Ação afirmativa: história e debates. Cadernos de Pesquisa, São Paulo, n. 117, p. 197-217, nov. 2002.

NASCIMENTO, Abdias; NASCIMENTO, Elisa Larkin. Reflexões sobre o movimento negro no Brasil, 1938-997. In: HUNTLEY, Lynn; GUIMARÃES, Antônio Sérgio A. (Org.). Tirando a máscara: ensaios sobre o racismo no Brasil. São Paulo: Paz e Terra, 2000. p. 203-234.

NASCIMENTO, Abdias do. O negro revoltado. Rio de Janeiro: Nova Fronteira, 1982.

PAIXÃO, Marcelo; ROSSETO, Irene; MONTOVANELE, Fabiana; CARVANO, Luiz M. (Org.). Relatório anual das desigualdades raciais no Brasil; 2009-2010. Rio de Janeiro: Ed. Garamond, 2010.

PEREIRA, Amilcar A. “O Mundo Negro”: a constituição do movimento negro contemporâneo no Brasil (1970-1995). 2010. Tese (Doutorado em História)-Universidade Federal Fluminense, Niterói, 2010.

QUEIROZ, Delcele M.; SANTOS, Jocélio T. Sistemas de cotas. Um debate. Dos dados à manutenção do privilégio e de poder. Educação e Sociedade, Campinas, v. 27, n. 96, p. 717-737, out. 2006. Edição especial.

RATTS, Alex. Encruzilhadas por todo o percurso: individualidade e coletividade no movimento negro de base acadêmica. In: PEREIRA, Amauri M.; SILVA, Joselina da (Org.). Movimento Negro Brasileiro: escritos sobre os sentidos de democracia e justiça social no Brasil. Belo Horizonte: Nandyala, 2009. p. 81-108. 
No topo do mundo: Everest e ações afirmativas na Pós-Graduação

SANTOS, José Antônio dos. Prisioneiros da história: trajetórias intelectuais na imprensa negra meridional. 2011. Tese (Doutorado em História)-Pontíficia Universidade Católica do Rio Grande do Sul, Porto Alegre, 2011.

SILVA, Adriana Maria Paulo da. Aprender com perfeição e sem coação: uma escola para meninos pretos e Pardos na Corte. Brasília, DF: Editora Plano, 2000.

SILVA JR., Hédio. Direito de igualdade racial. São Paulo: Juarez de Oliveira, 2002.

SIQUEIRA, José J. Os Congressos Afro-Brasileiros de 1934 e 1937 face ao I Congresso do Negro Brasileiro de 1950: rupturas e impasses. Augustus, Rio de Janeiro, v. 10, n. 21, p. 41-49, jul./dez. 2009.

SOUZA, Jessé (Org.). Multiculturalismo e racismo: uma comparação Brasil-Estados Unidos. Brasília, DF: Paralelo 15 Editores, 1997.

TOKARNIA, Mariana. Negros representam 28,9\% dos alunos da pós-graduação. Agência Brasil, Brasília, DF, 13 maio 2015. Disponível em: <http://agenciabrasil. ebc.com.br/educacao/noticia/2015-05/negros-representam-289-dos-alunos-da-posgraduacao>. Acesso em: 20 jul. 2016.

VALVERDE, Danielle O.; STOCCO, Lauro. Notas para interpretação das desigualdades raciais na educação. Estudos Feministas, Florianópolis, v. 17, n. 3, p. 909-920, set./dez. 2009.

Recebido em: 20/07/2016 Aprovado em: 01/10/2016 